\title{
Role of bile salts in fat malabsorption of premature infants
}

\author{
E. SIGNER, ^ G. M. MURPHY, SUSAN EDKINS, and CHARLOTTE M. ANDERSON \\ From the Institute of Child Health, University of Birmingham
}

\begin{abstract}
Signer, E., Murphy, G. M., Edkins, S., and Anderson, C. M. (1974). Archives of Disease in Childhood, 49, 174. Role of bile salts in fat malabsorption of premature infants. Eighteen premature infants were studied. 9 were fed with human milk and 9 with a modified cow's milk. Subsequent to a 72-hour fat balance, a duodenal intubation was performed on the 14th day of life. Total bile acids were determined in serial duodenal aspirates before and after a milk feed. Bile acid excretion in the faeces during a 72-hour period was also measured.

Infants fed with human milk absorbed fat better (mean fat absorption coefficient, $75 \%$ ) than those receiving a cow's milk formula (mean fat absorption coefficient, $60 \%$ ). In both groups the bile acid concentrations after a meal were often less than that required for the formation of micellar solutions and solubilization of fat (i.e. $<2 \mathrm{mmol} / \mathrm{l}$.). With human milk, a reasonable fat absorption occurred even with bile acid levels below the critical micellar concentration. In the infants fed with the cow's milk formula, impaired fat absorption was correlated with low bile acid levels.

Infants on human milk excreted less bile acids in the stool (mean, $41.9 \mu \mathrm{mol} / \mathrm{kg}$ per $24 \mathrm{hr}$ ) than did infants fed with the cow's milk formula (mean, $72.4 \mu \mathrm{mol} / \mathrm{kg} \mathrm{per} 24 \mathrm{hr}$ ). In both groups the faecal loss of bile acids was increased compared with that in older infants and children.
\end{abstract}

It is well known that newborn infants exhibit malabsorption of fat. The extent of the steatorrhoea is dependent on the type of ingested fat. In term neonates the absorption of human milk fat is 85 to $90 \%$ (Welsch et al., 1965; Widdowson, 1965), whereas the absorption of cow's milk fat is only 60 to $70 \%$ (Fomon, 1967). Malabsorption of fat is particularly marked in premature infants. Such infants have been shown to absorb on the average 70 to $75 \%$ of human milk fat and 45 to $60 \%$ of butterfat (Tidwell et al., 1935; Davidson and Bauer, 1960). Optimal absorption of dietary lipid requires the presence of adequate amounts of bile acids in the intestinal lumen (Hofmann, 1963). There is increasing evidence that bile acid concentrations in the duodenal juice of term neonates are often very low (i.e. $<3 \mathrm{mmol} / 1$.) (Poley et al., 1964; Norman, Strandvik, and Ojamäe, 1972; Challacombe, Edkins, and Brown, in preparation). More recently the bile salt pool size in newborn infants has been reported

Received 7 September 1973.

^Present address: Basler Kinderspital, CH-4000 Basle, Switzerland. to be conspicuously reduced relative to that in adults (Watkins et al., 1973a). All these findings suggest that low intraluminal bile acid concentrations during digestion of a feed may be one of the main factors involved in the fat malabsorption of the newborn.

This study was undertaken to examine the role of duodenal bile acid concentrations and diet in the steatorrhoea of premature infants.

\section{Materials and methods}

Clinical. 18 premature infants were studied (Table I). Group A (9 infants) was fed with human milk (i.e.

TABLE I

Study groups

\begin{tabular}{|c|c|c|}
\hline Group & A & B \\
\hline $\begin{array}{l}\text { Number } \\
\text { Feed } \\
\text { Gestational age (wk) } \\
\text { Birthweight (g) }\end{array}$ & $\begin{array}{l}\quad 9 \\
\text { Human milk } \\
\text { Mean } 35 \\
\text { Range } 32-38 \\
\text { Mean } 1735 \\
\text { Range } 1134-2240\end{array}$ & \begin{tabular}{l}
\multicolumn{1}{c}{9} \\
Cow's milk \\
Mean 37 \\
Range $35-39$ \\
Mean 2155 \\
Range $1870-2690$
\end{tabular} \\
\hline
\end{tabular}


pooled, pasteurized, expressed breast milk). Group B (9 infants) was fed with a modified cow's milk formula (Ostermilk No. $1^{\star}$ ). The mean gestational age and the mean birthweight in group A were both slightly less than those in group B, due to the policy of feeding the smaller babies with human milk rather than with the cow's milk formula. All the infants selected for the study were healthy premature infants without any perinatal problems. All infants received vitamin $\mathrm{K}$ after delivery. No further medications were given during the first 2 weeks of life. None who required phototherapy for hyperbilirubinaemia at any stage was included in the study. All infants were investigated at the same age and under the same conditions, and permission for studying them was obtained from the parents. All were being fed by nasogastric tube.

A 72-hour fat balance was done, lasting from the 11th to the 14th day of life. The milk required for this 72-hour period was prepared in advance for each infant and kept frozen until used. A representative sample of this milk pool was kept for subsequent fat estimation. During the fat balance the infants were fed 3-hourly via nasogastric tube using a syringe, which allowed accurate measurements of the milk intake. The stools were collected in polyethylene sheets and immediately frozen. No ointments were used in the perianal region. Since wide variations in daily frequency of bowel movements are uncommon in this age group, a stool marker was considered unnecessary.

On the 14th day of life, immediately after finishing the 72-hour fat balance, a duodenal intubation was performed. Single lumen tubes (Argyle $5 \mathrm{FR}, 91 \mathrm{~cm}$ long) were used. The tip of the tube was cut off and a small gold bead ( $4 \mathrm{~mm}$ long, $1 \mathrm{~mm}$ in diameter, about 0.25 g) was fixed at the end to give additional weight in order to facilitate passage into the duodenum (Challacombe, Richardson, and Anderson, 1974). Two to three holes were made proximal to the gold bead. Intubation was performed via the nose in all but 2 infants, oral intubation being used in the latter. With the infant in supine position the tube was introduced 10 to $15 \mathrm{~cm}$, after which the infant was turned on its right side and the tube gently pushed forward until the distance between nose and catheter tip was 35 to $40 \mathrm{~cm}$. The position of the tube was checked by repeated aspiration of fluid and estimation of $p \mathrm{H}$. Stomach $p \mathrm{H}$ was in each instance below 4. In most cases the duodenum was reached after 20 to 30 minutes, when bile-stained fluid began to appear with a $p \mathrm{H}$ of 6 to 7 . Only in 3 cases was $x$-ray examination necessary to be sure of the correct position of the tube.

A 'fasting' sample was collected between 2 and 3 hours after the last feed and care was taken to remove not more than $0.5 \mathrm{ml}$ duodenal juice at this stage. 3 hours after the last feed a test meal of $50 \mathrm{ml}$ human milk (group A) or Ostermilk No. 1 (group B) was given by nasogastric tube in 10 minutes. After the meal serial samples were taken

\footnotetext{
$\star$ Dried half-cream cow's milk with added lactose, iron, and vitamins A, C, D. Composition per $100 \mathrm{ml}$ reconstituted feed: protein $2.3 \mathrm{~g}$, fat $2.4 \mathrm{~g}$, lactose $7.0 \mathrm{~g}$, cal 60 . Glaxo Laboratories Ltd., Greenford, Middlesex.
}

during 3 hours as follows: during the first hour six samples at 10 -minute intervals; during the second hour three samples at 20-minute intervals; and during the third hour two samples at 30-minute intervals. All specimens were immediately frozen on dry ice and kept in the deep freeze until analysed.

Laboratory. Total $3 \alpha$-hydroxy bile acid concentrations of duodenal contents and faecal homogenates were determined using the enzymatic fluorimetric technique (Murphy, Billing, and Baron, 1970). Each sample was analysed in duplicate. Precision of duplicate estimations on duodenal samples was as follows: for concentrations $<0.5 \mathrm{mmol} / \mathrm{l}$. the coefficient of variation was $14 \%$, for concentrations $0.5-1.0 \mathrm{mmol} / 1.3 \%$, and for concentrations $>1.0 \mathrm{mmol} / 1 .<2 \%$. The mean recovery of known amounts of bile acids added to duodenal samples before estimation was $98.8 \%$, $\mathrm{SD} \pm 6 \cdot 7 \%$. Between-batch precision, as indicated by estimation of the same sample of duodenal contents with each different batch, was mean value $3.9 \mathrm{mmol} / \mathrm{l}$., coefficient of variation $4 \%$. For faecal bile acids precision of concentrations $<50 \mu \mathrm{mol} / \mathrm{l}$. was $25 \%$, between $50-100 \mu \mathrm{mol} / \mathrm{l} .12 \%$, and for values $>100$ $\mu \mathrm{mol} / 1 .>10 \%$. The mean recovery of known amounts of bile acids added to faecal homogenates before extraction and estimation was $98 \%, S D \pm 16 \%$.

Faecal fat was determined by the method of van de Kamer, ten Bokkel Huinink, and Weijers (1949) as modified by Anderson et al. (1952).

\section{Results}

Fat absorption. The results of the fat balances are shown in Fig. 1 and Table II. The mean fat absorption coefficient in the infants fed with human milk was $75 \% \pm 5 \cdot 9$ (range $65-82 \%$ ), whereas in the infants fed with cow's milk formula the mean was $60 \% \pm 10 \cdot 8$ (range $47-80 \%$ ). The better

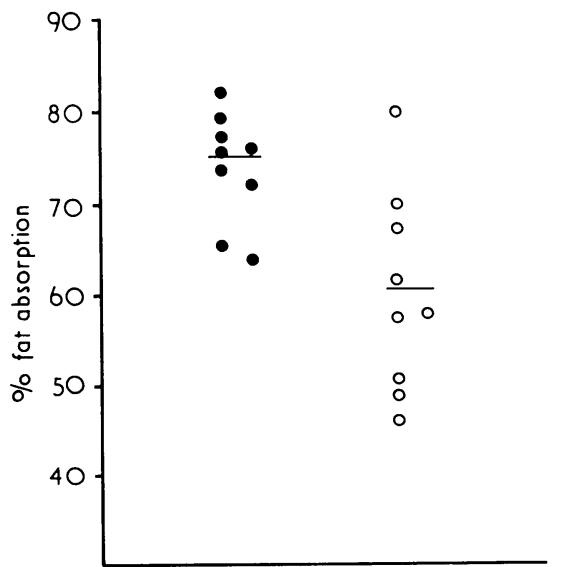

FIG. 1.-Distribution of fat absorption coefficients in 18 premature infants. - Human milk, $\bigcirc$ cow's milk (Ostermilk No. 1). Horizontal lines indicate means. 
TABLE II

Clinical data, fat absorption coefficient (FAC), and bile acid concentrations in the duodenum before and after a test meal (mean of the first six 10-minute samples)

\begin{tabular}{|c|c|c|c|c|c|c|}
\hline Cases & Sex & $\begin{array}{l}\text { Gestational age } \\
(\mathbf{w k})\end{array}$ & Birthweight (g) & FAC $(\%)$ & $\begin{array}{l}\text { Total bile acids } \\
\quad \text { (fasting) }\end{array}$ & $\begin{array}{l}\text { Bile acids (mmol/l.) } \\
\text { after meal } \bar{x} / 0-60\end{array}$ \\
\hline \multicolumn{7}{|c|}{ Group $A$ (human milk) } \\
\hline 1 & $\mathbf{F}$ & 36 & 2240 & $77 \cdot 4$ & $6 \cdot 9$ & $2 \cdot 2$ \\
\hline 2 & $M$ & 32 & 1134 & $65 \cdot 2$ & $6 \cdot 1$ & $1 \cdot 35$ \\
\hline 3 & $\mathrm{~F}$ & 37 & 2098 & $72 \cdot 0$ & $1 \cdot 17$ & $1 \cdot 78$ \\
\hline 4 & $\mathrm{M}$ & 38 & 2163 & $76 \cdot 0$ & $3 \cdot 38$ & $3 \cdot 19$ \\
\hline 5 & $\mathbf{M}$ & 33 & 1418 & $78 \cdot 7$ & 0.44 & 0.95 \\
\hline 6 & $\mathbf{M}$ & 35 & 1530 & $64 \cdot 7$ & $3 \cdot 16$ & $2 \cdot 09$ \\
\hline 7 & $\mathrm{~F}$ & 35 & 1559 & $73 \cdot 5$ & $1 \cdot 21$ & $1 \cdot 33$ \\
\hline 8 & $\mathrm{~F}$ & 33 & 1474 & $82 \cdot 4$ & $3 \cdot 67$ & 1.93 \\
\hline 9 & $\mathbf{M}$ & 36 & 2198 & $75 \cdot 4$ & $8 \cdot 17$ & $2 \cdot 02$ \\
\hline \multicolumn{7}{|c|}{ Group $B$ (Ostermilk No. I) } \\
\hline 1 & $\mathrm{~F}$ & 38 & 2690 & $46 \cdot 8$ & $6 \cdot 7$ & $1 \cdot 05$ \\
\hline 2 & M & 37 & 2041 & $61 \cdot 7$ & $6 \cdot 15$ & $2 \cdot 24$ \\
\hline 3 & $\mathbf{M}$ & 38 & 2296 & $69 \cdot 9$ & $8 \cdot 3$ & $4 \cdot 74$ \\
\hline 4 & $\mathrm{~F}$ & 36 & 2215 & $51 \cdot 0$ & $1 \cdot 65$ & 0.49 \\
\hline 5 & $\mathrm{~F}$ & 39 & 2150 & $80 \cdot 2$ & $23 \cdot 3$ & $5 \cdot 54$ \\
\hline 6 & F & 35 & 1870 & $49 \cdot 4$ & $7 \cdot 76$ & $1 \cdot 83$ \\
\hline 7 & $\mathrm{M}$ & 38 & 2055 & $58 \cdot 0$ & $6 \cdot 18$ & $1 \cdot 79$ \\
\hline 8 & $\mathrm{M}$ & 38 & 1928 & $67 \cdot 0$ & $13 \cdot 0$ & $4 \cdot 41$ \\
\hline 9 & $\mathrm{M}$ & 36 & 2268 & $57 \cdot 8$ & $6 \cdot 6$ & $1 \cdot 59$ \\
\hline
\end{tabular}

absorption for human milk fat is statistically significant $(t=3 \cdot 34, P<0 \cdot 01)$. A greater variation of fat absorption was found in the group receiving cow's milk, compared to that receiving human milk.

Bile acid concentrations in the duodenal samples.

'Fasting' samples. The total bile acid concentrations in the duodenal juice 2 hours after the last feed on the 14th day of life are listed in Table II. Infants fed with cow's milk showed generally higher values (mean $8 \cdot 8 \pm 6 \cdot 1 \mathrm{mmol} / \mathrm{l}$.) than the infants on human breast milk (mean $3 \cdot 8 \pm 2 \cdot 7 \mathrm{mmol} / \mathrm{l}$., $\mathrm{t}=2 \cdot 24, \mathrm{P}<0 \cdot 1$ ). Of group B (Ostermilk No. 1) 8 of 9 infants had 'fasting' levels above the critical micellar concentration ( $4 \mathrm{mmol} / \mathrm{l}$.), whereas in group A (human milk) only 3 of 9 babies achieved values above this level.

Samples after the meal. Fig. 2 shows the total bile acid levels in all subjects, before the meal ('fasting') and at 10,20,40,60, and 120 minutes after a test meal of $50 \mathrm{ml}$ milk. In 2 infants the material sampled between 0 and 10 minutes after the meal was not sufficient for analysis. It can be seen from Fig. 2 that in the first 60 minutes after the meal the bile acid levels were below the limit found in normal subjects during a meal, i.e. below $4 \mathrm{mmol} / \mathrm{l}$. in all but 3 infants. In a considerable proportion of the infants the bile acid concentrations were below the critical micellar concentration of $2 \mathrm{mmol} / \mathrm{l}$.

In Fig. 3 the mean values of the bile acid concentrations after a test meal are shown separately for the two groups. In addition to the higher

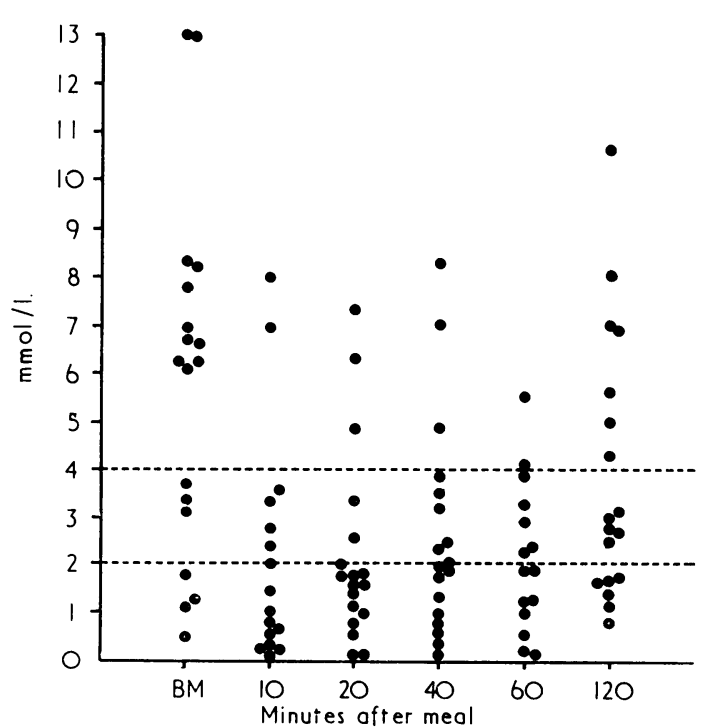

FIG. 2.-Distribution of total bile acid concentrations in duodenal contents before $(B M)$ and at different times after a test meal in 18 premature infants. 
fasting levels the infants on cow's milk achieved generally higher bile acid concentrations during the digestion phase of the test meal than infants fed with human milk. 3 hours after the test meal the bile acid concentrations in the duodenum had returned to approximately the same levels as those found in the 'fasting' sample.

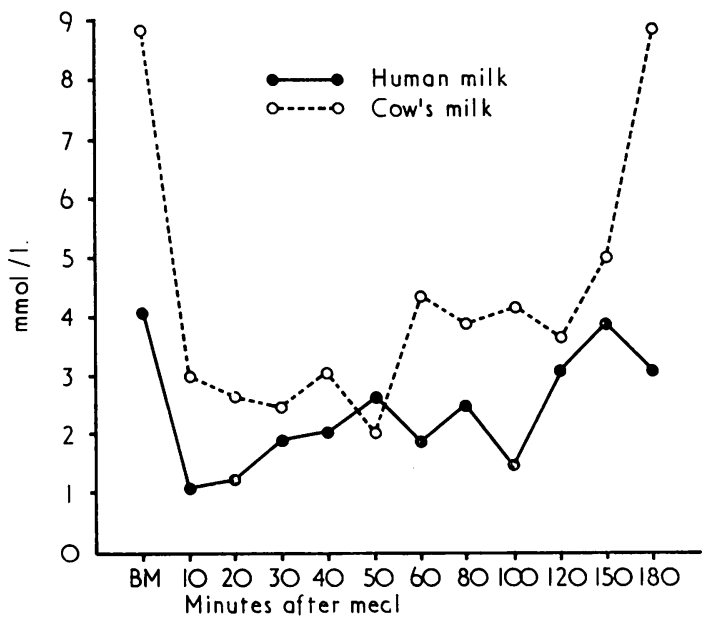

FIG. 3.-Mean bile acid concentrations before (BM) and at different times after a test meal. - Mean of 9 infants fed with human milk; $O$ mean of 9 infants fed with cow's milk (Ostermilk No. 1).

Correlation between bile acid concentrations in the duodenum and fat absorption coefficient (Fig. 4). It was assumed that for lipid absorption the presence of bile acids in the chymus was most important during the first 60 minutes after the milk feed. We therefore calculated the mean bile acid concentrations during the first 60 minutes (derived from the six 10-minute samples collected during this period) for each infant and compared it with the corresponding fat absorption coefficient (Table II). In the infants fed with human milk no correlation could be found between bile acid levels and the fat absorption coefficient $(r=0 \cdot 10)$, whereas in the prematures fed on cow's milk a correlation existed between the degree of fat absorption and the mean bile acid concentration during the first 60 minutes after the test meal $(r=0.92)$. As shown in Fig. 4, the coefficient of fat absorption in infants fed with human milk was 65 to $80 \%$ even with bile acid concentrations below 2 $\mathrm{mmol} / \mathrm{l}$. On the other hand all the babies on cow's milk with bile acid levels below $2 \mathrm{mmol} / 1$. absorbed less than $60 \%$ of the ingested fat. This point is further illustrated by the results obtained in a pair of

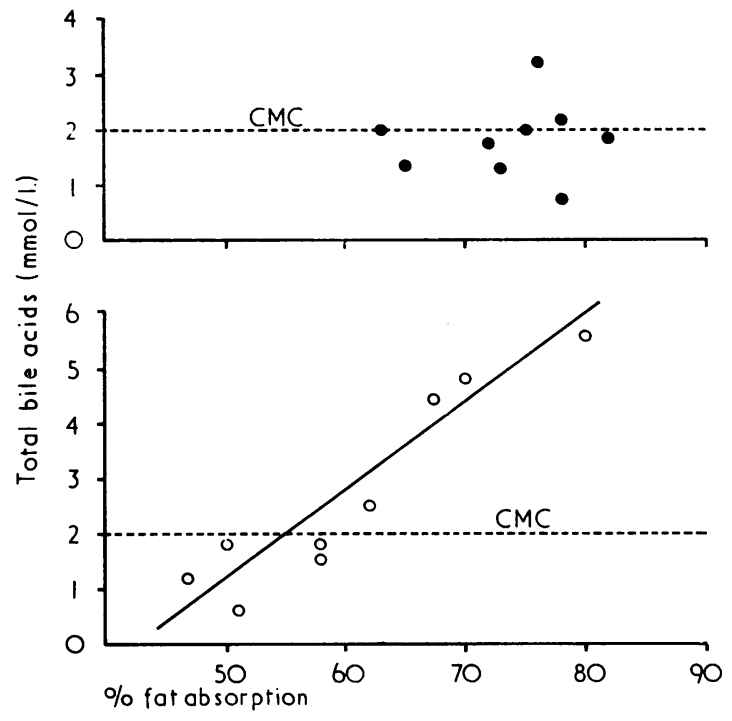

FIG. 4.-Correlation between fat absorption coefficients and average bile acid concentrations in duodenal contents in the first 60 minutes after a test meal (calculated from the first 6 samples after the meal). Infants fed with human milk; $\bigcirc$ infants fed with cow's milk (Ostermilk No. 1); CMC, critical micellar concentration.

identical twins (Fig. 5). One twin was fed with cow's milk, the other with human milk. The bile acid concentrations during the first 100 minutes after the meal were practically the same in both infants. The fat absorption coefficient was $65 \%$

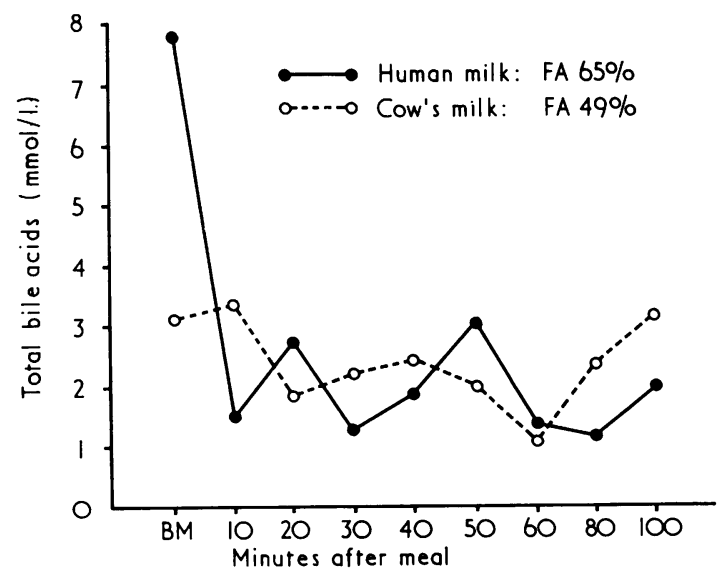

FIG. 5.-Total bile acid concentrations before (BM) and after a test meal in identical twins. Twin fed with human milk: fat absorption coefficient $(F A)=65 \%$; $\bigcirc$ twin fed with cow's milk (Ostermilk No. 1): fat absorption coefficient $(F A)=49 \%$. 
with human milk and only $49 \%$ with the cow's milk formula.

Bile acid excretion in the faeces. A significant difference in faecal bile acid excretion was found between the two groups (Table III). Infants on human milk excreted less bile acid in the stool (mean $41 \cdot 9 \pm 10 \cdot 7 \mu \mathrm{mol} / \mathrm{kg}$ per 24 hours) than did those fed with cow's milk formula (mean $72 \cdot 4 \pm 27 \cdot 4$ $\mu \mathrm{mol} / \mathrm{kg}$ per 24 hours, $\mathrm{t}=2.94, \mathrm{P}<0.02)$. No correlation was found between the fat absorption coefficient or the amount of excreted fat per day and the amount of excreted bile acids. There appeared to be no relation between the duodenal bile acid concentrations and the faecal bile acid excretion.

\section{Discussion}

Optimal absorption of lipid requires the synergistic action of (i) hydrolysis of dietary triglyceride by pancreatic lipase, (ii) solubilization of the products of hydrolysis by mixed micelles, and (iii) efficient absorption across the intestinal mucosa. Disturbance of one or more of these factors could explain the steatorrhoea of many premature and term infants.

The exocrine pancreatic function of premature infants, as measured by exogenous pancreozyminsecretin stimulation, is well developed at the age of 1 week (Zoppi et al., 1972). On the other hand, low lipase concentrations have been reported in the duodenal juice of term newborns after a test meal of human milk (Norman et al., 1972). Diminished response of the exocrine pancreas to a milk feed may therefore be a contributory factor to the steatorrhoea of premature and term infants.

The role of bile salts during the digestion and absorption of fat embraces all three factors mentioned above. Bile salts facilitate the action of lipase by emulsification of the dietary lipids (Frazer, Schulman, and Stewart, 1944), by activation of lipase (Borgström, 1954; Desnuelle, 1961), by activation of co-lipase (Borgström and Erlanson, 1971), and by the solubilization of the end products of pancreatic lipolysis (Morgan and Hoffman, 1971). The latter, i.e. fatty acids and monoglycerides, are incorporated into mixed micelles which allow close contact between the lipid and the absorptive membrane, thus resulting in enhanced lipid absorption (Hofmann, 1963).

To take part in micelle formation bile salts must be present in concentrations that exceed a certain critical value-the critical micellar concentration (CMC). The CMC of a mixture of bile acids under conditions closely simulating those in the intestinal lumen is 1 to $2 \mathrm{mmol} / \mathrm{l}$. (Hofmann, 1963). In theory the optimal absorption of fat requires at least this concentration of bile salts. It has been proposed (Badley, Murphy, and Bouchier, 1969) that in the human being the concentration of bile salts in the lumen should be in excess of $4 \mathrm{mmol} / \mathrm{l}$., the lower limit found in normal subjects during a meal (Sjövall, 1959; van Deest et al., 1968).

TABLE III

Bile acid excretion in the faeces

\begin{tabular}{|c|c|c|c|c|c|}
\hline \multirow{2}{*}{ Cases } & \multicolumn{4}{|c|}{ Faecal bile acid excretion $(\mu \mathrm{mol})$} & \multirow{2}{*}{$\mu \mathrm{mol} / \mathrm{kg}$ per $24 \mathrm{hr}$} \\
\hline & Day 1 & Day 2 & Day 3 & Mean $/ 24 \mathrm{hr}$ & \\
\hline \multicolumn{6}{|c|}{ Group A (human milk) } \\
\hline 1 & $121 \cdot 0$ & - & - & $121 \cdot 0$ & $53 \cdot 0$ \\
\hline 2 & $27 \cdot 5$ & $55 \cdot 0$ & $159 \cdot 5$ & $53 \cdot 2$ & $50 \cdot 7$ \\
\hline 3 & $135 \cdot 0$ & $110 \cdot 0$ & $96 \cdot 0$ & $113 \cdot 7$ & $58 \cdot 3$ \\
\hline 4 & $74 \cdot 0$ & $70 \cdot 0$ & $59 \cdot 0$ & $67 \cdot 7$ & $33 \cdot 2$ \\
\hline 5 & $66 \cdot 0$ & $67 \cdot 4$ & $51 \cdot 7$ & $61 \cdot 7$ & $46 \cdot 4$ \\
\hline 6 & $55 \cdot 0$ & $82 \cdot 0$ & $58 \cdot 0$ & $65 \cdot 0$ & $40 \cdot 6$ \\
\hline 7 & $55 \cdot 0$ & $24 \cdot 0$ & $79 \cdot 0$ & $52 \cdot 7$ & $32 \cdot 5$ \\
\hline 8 & $51 \cdot 2$ & $44 \cdot 0$ & $66 \cdot 0$ & $53 \cdot 8$ & $35 \cdot 9$ \\
\hline 9 & $48 \cdot 1$ & $71 \cdot 5$ & $55 \cdot 6$ & $58 \cdot 4$ & $27 \cdot 2$ \\
\hline \multicolumn{6}{|c|}{ Group B (Ostermilk No. l) } \\
\hline 1 & $764 \cdot 5$ & $58 \cdot 2$ & $22 \cdot 0$ & $281 \cdot 6$ & $107 \cdot 5$ \\
\hline 2 & $110 \cdot 0$ & $123 \cdot 0$ & $156 \cdot 0$ & $129 \cdot 7$ & $59 \cdot 2$ \\
\hline 3 & $255 \cdot 0$ & $259 \cdot 0$ & $232 \cdot 0$ & $248 \cdot 7$ & $108 \cdot 6$ \\
\hline 4 & $141 \cdot 0$ & $154 \cdot 0$ & $162 \cdot 0$ & $152 \cdot 3$ & $69 \cdot 5$ \\
\hline 5 & $189 \cdot 8$ & $129 \cdot 2$ & $179 \cdot 9$ & $166 \cdot 3$ & $75 \cdot 6$ \\
\hline 6 & $110 \cdot 0$ & $60 \cdot 5$ & $80 \cdot 0$ & $83 \cdot 5$ & $41 \cdot 5$ \\
\hline 7 & $132 \cdot 0$ & $107 \cdot 0$ & $174 \cdot 0$ & $137 \cdot 7$ & $62 \cdot 3$ \\
\hline 8 & $179 \cdot 3$ & $169 \cdot 0$ & $185 \cdot 9$ & $178 \cdot 0$ & $86 \cdot 4$ \\
\hline 9 & $61 \cdot 9$ & $71 \cdot 5$ & $55 \cdot 6$ & $58 \cdot 4$ & $27 \cdot 2$ \\
\hline
\end{tabular}


In the present study only 3 of the 18 premature babies maintained bile salt concentrations above 4 $\mathrm{mmol} / \mathrm{l}$. during the digestion of a milk feed, in 10 of the infants the mean bile salt concentration during the first hour after the meal was even less than 2 $\mathrm{mmol} / \mathrm{l}$. These data indicate that many premature infants have a deficiency of duodenal bile salts. The mechanism responsible for this remains obscure.

One factor that may be responsible for duodenal bile salt deficiency is small pool size. Using nonradioactive isotope techniques, Watkins et al. (1973b) have shown that the bile salt pool in newborn and premature infants is conspicuously reduced relative to that in normal adults. Other explanations, however, of bile salt deficiency can also be proposed. The capacity of the gallbladder to concentrate bile may not be fully developed in the neonate and low bile salt concentrations have been reported in the gallbladder content of the newborn (Bongiovanni, 1965). In this report the common practice of feeding infants every 3 hours may prevent efficient storage and concentration of gallbladder bile. The release of pancreozymin and the response of the gallbladder to pancreozymin may also be impaired in the premature infant. Yet another explanation for duodenal bile salt deficiency during a feed may be a lack of synchronization between gastric emptying and bile flow into the duodenum. Rapid gastric emptying has been reported to occur in the neonate (Norman et al., 1972).

In the present study premature infants fed with cow's milk exhibited higher bile acid concentrations, both in the 'fasting' state and after the meal, than those fed with human milk. This was probably due to the difference in gestational age in the two groups. Despite lower bile acid concentrations, infants fed with human milk absorbed fat better. It is clear that the absorption of the fat of human milk is less dependent on bile acids than that of cow's milk. In the infants fed with cow's milk, bile acid concentrations below $2 \mathrm{mmol} / \mathrm{l}$. during digestion were invariably associated with a fat absorption of less than $60 \%$, whereas with concentrations above 4 $\mathrm{mmol} / \mathrm{l}$. the fat absorption coefficient (FAC) was 67 to $80 \%$. No correlation between FAC and bile acid concentrations after a meal was found in the infants fed with human milk fat. Bile acid levels below 2 $\mathrm{mmol} / 1$. were still compatible with a fat absorption of 72 to $82 \%$. Human milk seems therefore to be well adapted to the state of primary bile salt deficiency, which is normally present in newborn infants.

The reasons why bile acids are less important for the absorption of human milk fat than they are for butterfat are not well understood. The better absorption of human milk fat has been attributed to the fact that it contains fewer saturated long-chain fatty acids and triglycerides of the $S_{3}$ type and more triglycerides of the $S U_{2}$ and $U_{3}$ types than butterfat. Shorter chain fatty acids and unsaturated fatty acids are split from the triglyceride molecule more easily than are the longer, saturated fatty acids (Fomon, 1967). Lipolysis of the triglyceride types occurring in human milk may be adequate even without assistance of bile salts. In addition, micellar solubilization may be less essential for unsaturated fatty acids than for saturated ones.

The deficiency of bile salts may be aggravated by increased faecal loss of bile acids. The premature infants in this study had increased excretion of faecal bile acids when compared with values previously reported (Weber et al., 1972) for older children. These authors have suggested that the presence of unhydrolysed triglycerides may result in increased faecal bile acid excretion. This observation is supported in the present study by the fact that premature infants fed cow's milk excreted more bile acids than those fed human milk. No correlation, however, was found between the amount of excreted bile acids and the fat excretion in the stools or the duodenal bile acid concentrations. The enhanced faecal loss of bile acids could be attributed to 'immaturity' of the active reabsorption in the ileum, to an increased number of enterohepatic circulations, or to an acceleration of the transit time.

Bile acids are not only important for optimal absorption of fat, especially butterfat, but also essential for the absorption of the fat soluble vitamins $A, D, E$, and $K$. The bile salt deficiency present in most premature babies leads almost certainly to malabsorption of these vitamins. Since vitamin $\mathrm{K}$ is given parenterally routinely after birth and most commercial milk products are enriched with the vitamins $A, D$, and $E$ in their water soluble form, symptoms of vitamin deficiency seldom occur in premature infants. However, vitamin $\mathbf{E}$ deficiency and haemolytic anaemia have been reported recently in premature infants receiving a modified cow's milk formula (not supplemented with vitamin E) (Lo, Frank, and Hitzig, 1973). Another probable consequence of bile salt deficiency is impaired absorption of calcium and magnesium due to the formation of insoluble soaps with fatty acids in the presence of steatorrhoea (Southgate $e t$ al., 1969; Bliss, Small, and Donaldson, 1972). Nutrition of newborn premature infants must, therefore, take into account the bile salt deficiency present in these babies. Human milk or 
commercially prepared formulas with a fat composition similar to that of human milk fat should be used. Supplementation of the diets with vitamin $A, D$, and $E$ is highly desirable.

We thank the paediatric consultants at Sorrento Maternity Hospital for allowing us to pursue this investigation in the Special Care Unit, and the nursing staff for their meticulous help in collection of specimens. E. S. was supported by a grant from the Swiss National Fund and S.E. by a grant from the Medical Research Council.

\section{REFERENCES}

Anderson, C. M., Frazer, A. C., French, J. M., Gerrard, J. W., Sammons, H. G., and Smellie, J. M. (1952). Coeliac disease: gastro-intestinal studies and the effect of dietary wheat flour. Lancet, 1, 836.

Badley, B. W. D., Murphy, G. M., and Bouchier, I. A. D. (1969), Intraluminal bile-salt deficiency in the pathogenesis of steatorrhoea. Lancet, 2, 400.

Bliss, C. M., Small, D. M., and Donaldson, R. M. (1972). The excretion of calcium and magnesium fatty acid soaps in steatorrhoea. (Abst.) Gastroenterology, 62, 724.

Bongiovanni, A. M. (1965). Bile acid content of gallbladder of infants, children and adults. Fournal of Clinical Endocrinology and Metabolism, 25, 678.

Borgström, B. (1954). Effect of taurocholic acid on the pH activity curve of rat pancreatic lipase. Biochimica et Biophysica Acta, $13,149$.

Borgström, B., and Erlanson, C. (1971). Pancreatic juice co-lipase: physiological importance. Biochimica et Biophysica Acta, 242, 509.

Challacombe, D. N., Richardson, J. M., and Anderson, C. M. (1974). Bacterial microflora of upper gastrointestinal tract in infants without diarrhoea. Archives of Disease in Childhood. (In the press.)

Davidson, M., and Bauer, C. H. (1960). Patterns of fat excretion in feces of premature infants fed various preparations of milk. Pediatrics, 25, 375.

Desnuelle, P. (1961). Pancreatic lipase. Advances in Enzymology, 23, 129.

Fomon, S. J. (1967). Infant nutrition. Saunders, Philadelphia.

Frazer, A. C., Schulman, J. H., and Stewart, H. C. (1944). Emulsification of fat in the intestine of the rat and its relationship to absorption. Fournal of Physiology, 103, 306.

Hofmann, A. F. (1963). The function of bile salts in fat absorption. Biochemical fournal, 89, 57.

Lo, S. S., Frank, D., and Hitzig, W. H. (1973). Vitamin E and haemolytic anaemia in premature infants. Archives of Disease in Childhood, 48, 360.
Morgan, R. G. H., and Hoffman, N. E. (1971). The interaction of lipase, lipase cofactor and bile salts in triglyceride hydrolysis. Biochimica et Biophysica Acta, 248, 143.

Murphy, G. M., Billing, B. H., and Baron, D. N. (1970). A fluorimetric and enzymatic method for the estimation of serum total bile acids. Fournal of Clinical Pathology, 23, 594.

Norman, A., Strandvik, B., and Ojamăe, O. (1972). Bile acids and pancreatic enzymes during absorption in the newborn. Acta Paediatrica Scandinavica, 61, 571.

Poley, J. R., Dower, J. C., Owen, C. A., Jr., and Stickler, G. B. (1964). Bile acids in infants and children. fournal of Laboratory and Clinical Medicine, 63, 838.

Sjövall, J. (1959). On the concentration of bile acids in the human intestine during absorption. Acta Physiologica Scandinavica, 46, 339.

Southgate, D. A. T., Widdowson, E. M., Smits, B. J., Cooke, W. T. Walker, C. H. M., and Mathers, N. P. (1969). Absorption and excretion of calcium and fat by young infants. Lancet, 1, 487

Tidwell, H. C., Holt, L. E., Jr., Farrow, H. L., and Neale, S. (1935) Studies in fat metabolism. II. Fat absorption in premature infants and twins. Fournal of Pediatrics, 6, 481.

van Deest, B. W., Fordtran, J. S., Morawski, S. G., and Wilson, J. D. (1968). Bile salt and micellar fat concentration in proximal small bowel contents of ileectomy patients. Fournal of Clinical Investigation, 47, 1314.

van de Kamer, J. H., ten Bokkel Huinink, H., and Weijers, H. A (1949). A rapid method for the determination of fat in faeces. fournal of Biological Chemistry, 177, 347.

Watkins, J. B., Ingall, D., Szczepanik, P., Klein, P. D., and Lester, R. (1973a). Bile-salt metabolism in the newborn. New England fournal of Medicine, 288, 431.

Watkins, J. B., Szczepanik, P., Gould, J., Klein, P. D., and Lester, R. (1973b). Bile salt kinetics in premature infants: an explanation for inefficient lipid absorption. Gastroenterology, 64, A-134/ 817.

Weber, A. M., Chartrand, L., Doyon, G., Gordon, S., and Roy, C. C. (1972). The quantitative determination of fecal bile acids in children by the enzymatic method. Clinica Chimica Acta, 39, 524.

Welsch, H., Heinz, F., Lagally, G., and Stuhlfauth, K. (1965). Fettresorption aus frauenmilch bei Neugeborenen. Klinische Wochenschrift, 43, 902.

Widdowson, E. M. (1965). Absorption and excretion of fat, nitrogen, and minerals from 'filled' milks by babies one week old. Lancet, 2, 1099.

Zoppi, G., Andreotti, G., Paino-Ferrara, F., Njai, D. M., and Gaburro, D. (1972). Exocrine pancreas function in premature and full term neonates. Pediatric Research, 6, 880.

Correspondence to Professor C. M. Anderson, Institute of Child Health, Francis Road, Birmingham B16 8ET. 